\title{
Modeling the condensation of sulfuric acid and water on the cylinder liner of a large two-stroke marine diesel engine
}

Cordtz, Rasmus Faurskov; Mayer, Stefan; Eskildsen, Svend S.; Schramm, Jesper

Published in:

Journal of Marine Science and Technology

Link to article, DOI:

10.1007/s00773-017-0455-9

Publication date:

2018

Document Version

Peer reviewed version

Link back to DTU Orbit

Citation $(A P A)$ :

Cordtz, R. F., Mayer, S., Eskildsen, S. S., \& Schramm, J. (2018). Modeling the condensation of sulfuric acid and water on the cylinder liner of a large two-stroke marine diesel engine. Journal of Marine Science and Technology, 23(1), 178-187. https://doi.org/10.1007/s00773-017-0455-9

\section{General rights}

Copyright and moral rights for the publications made accessible in the public portal are retained by the authors and/or other copyright owners and it is a condition of accessing publications that users recognise and abide by the legal requirements associated with these rights.

- Users may download and print one copy of any publication from the public portal for the purpose of private study or research.

- You may not further distribute the material or use it for any profit-making activity or commercial gain

- You may freely distribute the URL identifying the publication in the public portal 


\title{
Modeling the Condensation of Sulfuric \\ Acid and Water on the Cylinder Liner of a Large Two-Stroke Marine Diesel Engine
}

\author{
Rasmus Cordtz*†, Stefan Mayer ${ }^{\ddagger}$, Svend S. Eskildsen ${ }^{\ddagger}$ \& Jesper Schramm ${ }^{\dagger}$ \\ ${ }^{\dagger}$ Technical University of Denmark \\ ${ }^{\ddagger}$ MAN Diesel \& Turbo SE, Denmark
}

Keywords: Two-stoke marine engine, $\mathrm{H}_{2} \mathrm{O}-\mathrm{H}_{2} \mathrm{SO}_{4}$-Condensation, liner corrosion, Phenomenological modeling.

\begin{abstract}
Corrosive wear of cylinder liners in large two-stroke marine diesel engines that burn heavy fuel oil containing sulfur is coupled to the formation of gaseous sulfur trioxide $\left(\mathrm{SO}_{3}\right)$ and subsequent combined condensation of sulfuric acid $\left(\mathrm{H}_{2} \mathrm{SO}_{4}\right)$ and water $\left(\mathrm{H}_{2} \mathrm{O}\right)$ vapor. The present work seeks to address how fuel sulfur content, charge air humidity and liner temperature variations affects the deposition of water and sulfuric acid at low load operation. A phenomenological engine model is applied to simulate the formation of cylinder/bulk gas combustion products and dew points comply with $\mathrm{H}_{2} \mathrm{O}-\mathrm{H}_{2} \mathrm{SO}_{4}$ vapor liquid equilibrium. By assuming homogenous cylinder gas mixtures condensation is modeled using a convective heat and mass transfer analogy combined with realistic liner temperature profiles. Condensation of water is significantly altered by the liner temperature and charge air humidity while sulfuric acid condensation (the order is a few mg per cylinder every cycle) is proportional to the fuel sulfur content. Condensation takes place primarily in the upper part of the cylinder liner where a reduction of the surface temperature or saturated charge air provides that the deposited acid can be highly diluted with water.
\end{abstract}




\section{INTRODUCTION}

Combustion of heavy fuel oil with sulfur in marine diesel engines involves the formation of gaseous sulfur trioxide $\left(\mathrm{SO}_{3}\right)$ and sulfur dioxide $\left(\mathrm{SO}_{2}\right)$. Experimental[1,2] and theoretical work[3] shows that $\mathrm{SO}_{2}$ is the primary sulfur compound and only a few percent is converted to $\mathrm{SO}_{3}$. The $\mathrm{SO}_{3}$ is however corrosive since it combines with water vapor[4] to form gaseous sulfuric acid $\left(\mathrm{H}_{2} \mathrm{SO}_{4}\right)$. If the liner surface temperature is lower than the sulfuric acid dew point $\mathrm{H}_{2} \mathrm{SO}_{4}$ and $\mathrm{H}_{2} \mathrm{O}$ may condense on it and promote corrosion. Different empirical correlations describe the sulfuric acid dew point in terms of the $\mathrm{H}_{2} \mathrm{SO}_{4}$ and $\mathrm{H}_{2} \mathrm{O}$ vapor pressure[5,6]. Other approaches use semi empirical activity coefficient models[7-12] to describe the Vapor Liquid Equilibrium (VLE) of the binary $\mathrm{H}_{2} \mathrm{O}-\mathrm{H}_{2} \mathrm{SO}_{4}$ mixture. Uncontrolled corrosive attack can significantly reduce the life time of the cast iron cylinder liners in large two-stroke marine engines. In practice the lube oil film on the liner surface (distributed by the moving piston) serves to hamper corrosion through base additives. Schramm[13] formulated a 1D model of sulfuric acid and base diffusion through the film and reported that the acid is efficiently neutralized. However, deposited acid was based on estimates and the influence of water was not considered. Moreover lube oil absorption of $\mathrm{SO}_{2}$ in the presence of water may add to corrosion due to the formation of sulfurous acid[14]. Nagaki[15] modeled $\mathrm{SO}_{2}$ uptake in an oil film, compared results with experimental wear rates of piston rings and concluded that $\mathrm{SO}_{2}$ increases wear. Anyway, the solubility of $\mathrm{SO}_{2}$ depends on the oil type. It is e.g. much more soluble in motor oils than in mineral oils[16]. At room temperature $\mathrm{SO}_{2}$ is found to be soluble in water[17] but to a much smaller extend at the liner temperature $\left(\approx 100{ }^{\circ} \mathrm{C}\right)$ that is restricted due to issues of the oil performance.

It is accepted that the presence of fuel sulfur leads to increased wear/liner corrosion but the impact of $\mathrm{SO}_{2}$ relative to $\mathrm{H}_{2} \mathrm{SO}_{4}$ is not clear. Little is also known about the order of $\mathrm{H}_{2} \mathrm{O}$ and $\mathrm{H}_{2} \mathrm{SO}_{4}$ condensation. Teetz[18] formulated a corrosive threat factor (without modeling condensation) based on the partial pressures of $\mathrm{H}_{2} \mathrm{O}$ and $\mathrm{H}_{2} \mathrm{SO}_{4}$ in the cylinder gas and argued that the thread is high in 
the top of the liner. For gas coolers with various geometries sulfuric acid condensation has been modeled using the Chilton-Colburn-analogy[19-21]. The analogy couples convective heat and mass transfer. In a numerical study on tubular cooler stacks Jeong[20] demonstrated that the analogy provides reasonable agreement with experimental data of $\mathrm{H}_{2} \mathrm{O}-\mathrm{H}_{2} \mathrm{SO}_{4}$ condensation. Similarly, Land[22] examined sulfuric acid condensation on the cooled probe head of a dew point meter and demonstrated that condensation correlates with the heat transfer as long as acid mists are not formed. Mist forms due to abrupt gas cooling from a surface and reduces the deposition of acid as it tends to follow the gas streamlines. Peak condensation rates were measured when the probe head was 20-30 ${ }^{\circ} \mathrm{C}$ lower than the sulfuric acid dew point. The overall instant heat transfer to the cylinder liner in a combustion engine is well-described[23-25] and typically based on simple Nusselt and Reynolds number correlations where model constants are fitted to match experimental heat loss data.

On the premise that non-condensable gasses act to hamper condensation Müller[26] introduced correction factors and formulated analytic expressions for the simultaneous condensation of sulfuric acid and water based on coupled heat and mass transfer. In a previous work[27] the authors studied the characteristics of sulfuric acid condensation (not water) on the cylinder liner of a large two-stroke marine diesel engine using fixed liner temperatures and applied Müllers expressions. The present work involves realistic liner temperatures and address condensation of both sulfuric acid and water. A phenomenological engine model[3] is used to simulate cylinder gas products. To retain the modeling level condensation is modeled through coupled heat and mass transfer where mist formation is neglected. Müllers corrections are found to have a faint influence in the present case, so the hampering effect of non-condensable gasses are ignored and VLE is assumed to exist at the gas-liquid interphase. Simulations demonstrate that condensation of sulfuric acid (through altered $\mathrm{SO}_{3}$ concentrations) varies with the degree of mixing between hot combustion products and fresh air in the cylinder. The engine model applies a calibrated yet simple mixing correlation to match 
experimental data of nitrogen oxides $\left(\mathrm{NO}_{\mathrm{x}}\right)$ in the exhaust. To assess its simplicity the effect of mixing in relation to condensation is addressed herein.

\subsection{ENGINE MODEL}

In this section, a brief description of the phenomenological engine model is provided. For further details, the reader is referred to the published material[3]. The model seeks to simulate a steady operating condition at $25 \%$ engine load (80 revolutions per minute) of the large two-stroke marine engine specified in Table 1 . The low load is considered in this study to match modern service engines in large container vessels. Model inputs include an experimental fuel burn rate curve (evaluated from a heat release analysis of a measured cylinder pressure) and charge air properties (pressure and temperature) in order to simulate a measured cylinder pressure trace and model realistic gas temperatures during the compression and the expansion stroke. In practice, not all burned gasses are replaced by fresh air during the subsequent cylinder scavenging. Thus, a reasonable residual gas fraction of $3 \% \mathrm{~m} / \mathrm{m}$ is applied as model input. The fuel is modeled as n-dodecane $\left(\mathrm{C}_{12} \mathrm{H}_{26}\right)$ including $2 \% \mathrm{~m} / \mathrm{m}$ non-bonded elemental sulfur (if not else is stated) and a detailed sulfur reaction mechanism[28-31] combined with the extended Zeldovich mechanism[32] is applied to simulate formation of combustion products including sulfur oxides and nitrogen oxides. By adapting the mixing between combustion products and fresh gas within the cylinder as explained hereafter the model is calibrated according to a measured $\mathrm{NO}_{\mathrm{x}}$ concentration.

Figure 1 presents the cylinder gas pressure and the approximated fuel burn rate curve with respect to the crank angle position after top dead center (CA ATDC). The point of fuel ignition $\left(\theta_{\text {ign }}\right)$ is close to the top dead center (TDC = 0 CA ATDC) and a large part of the fuel is burned within the first 20 CA ATDC that results in a sharp pressure rise before the pressure peaks at nearly 90 bar. 


\begin{tabular}{ll}
\hline Manufacturer & MAN B\&W Diesel \\
Type & 4T50ME-X \\
Number of cylinders & 4 \\
Bore/stroke & $500 \mathrm{~mm} / 2200 \mathrm{~mm}$ \\
Max speed & $123 \mathrm{RPM}$ \\
Max power & $7050 \mathrm{~kW}$
\end{tabular}

Table 1. Specifications of the modeled two-stroke marine diesel engine.
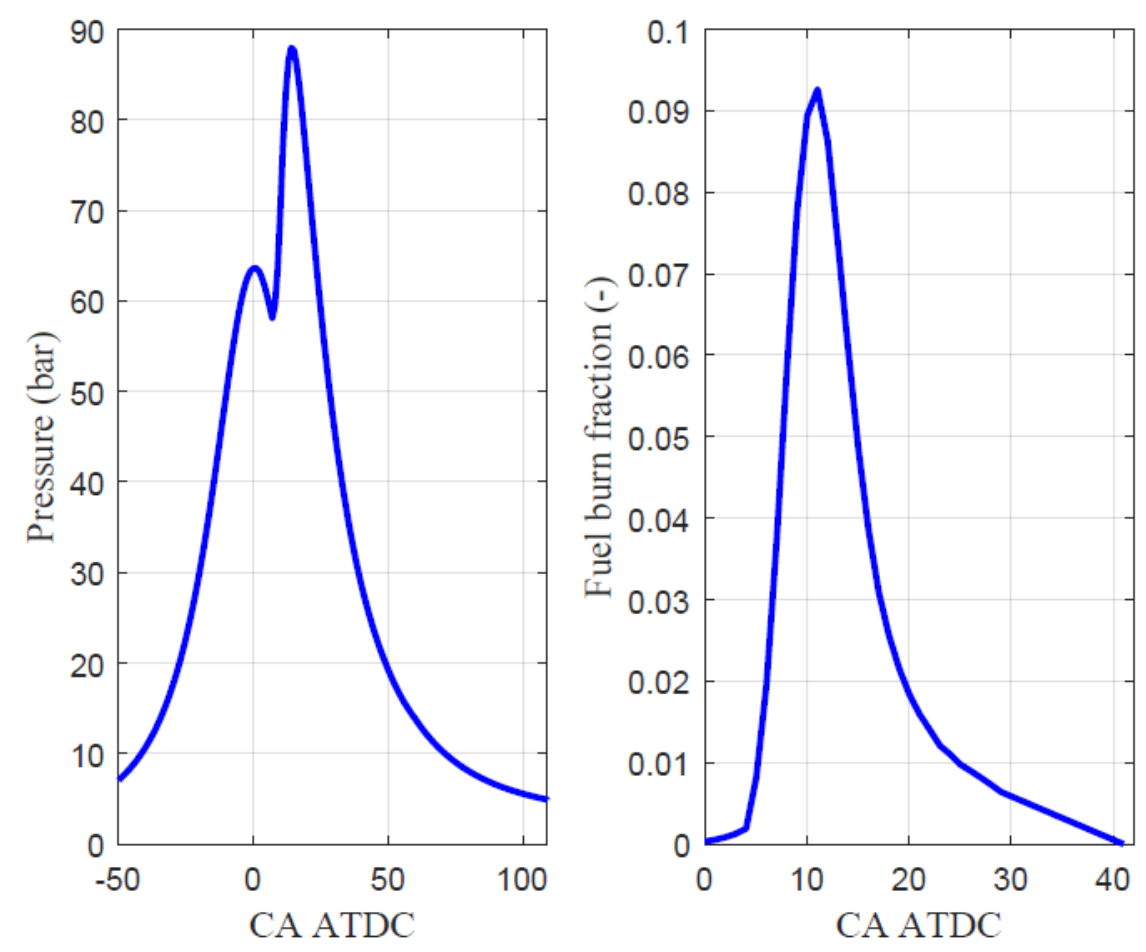

Figure 1. Cylinder gas pressure and fuel burn fraction relative to the crank angle position after top dead center (CA ATDC). The fuel burn fraction is calculated according to the rate of fuel heat release.

The complex nature of the liquid fuel spray and flame is not modeled in detail. The phenomenological engine model reproduces flame conditions alternatively by splitting injected fuel into multiple burned gas zones. At each crank angle from $\theta_{i g n}$ and until the combustion ends a new so-called burned zone (BZ) is formed. The share of the fuel burn fraction area (Figure 1) that is covered by the crank angle where a particular BZ is formed also represents the share of the injected fuel that is burned in the BZ. 
When a BZ is formed the fuel is stoichiometrically mixed with fresh gas and burns instantly. The fresh gas is composed largely by air (with or without water vapor) and includes the residual gas. The initial/flame temperature of a BZ is determined by conserving the total enthalpy of the BZ reactants (fuel and fresh gas) and the initial gas composition obey general chemical equilibrium. Fresh gas is hereafter mixed into the BZ (in a stepwise fashion) at each crank angle during the expansion stroke until the point where the exhaust valve opens (EVO). The mixing rate is assumed to be constant but should the local excess air ratio of a BZ at some point exceed the overall/trapped excess air ratio (defined by the trapped charge air mass and the fuel mass injected per cycle) then no more fresh gas is added to the BZ. No more fuel is added to a BZ and there is no gas exchange between BZ's either. Consequently, a BZ grows leaner throughout the expansion stroke and has no spatial location (0D model). The process of BZ's from the point of fuel ignition is illustrated at different time steps $(\Delta \theta=$ $1 C A D$ ) in Figure 2.

\begin{tabular}{|c|c|c|}
\hline CAD & Burned zones & Cycle phase \\
\hline - & & Ignition delay \\
\hline$\cdot$ & $\lambda=1$ & \\
\hline$\theta_{\text {ign }}$ & & Start of combustion \\
\hline $\begin{array}{l}\theta_{\mathrm{ign}}+\Delta \theta \\
\theta_{\mathrm{ign}}+2 \Delta \theta\end{array}$ & 3 & $\begin{array}{l}\text { Formation of new } \\
\text { burned zones and } \\
\text { fresh gas mixing }\end{array}$ \\
\hline . & & \\
\hline - & & \\
\hline - & & \\
\hline
\end{tabular}

Figure 2. Formation and progress of burned zones (number 1, 2, 3 etc.) at different computational steps $(\Delta \theta=1$ CAD) expressed in crank angle degrees (CAD). The $\lambda$-value represents the air fuel ratio of the burned zones. 
For each BZ a fresh gas threshold $m_{f g}$ is defined according to eq. 1 that is used to scale the rate of fresh gas mixing ( $\dot{\mathrm{m}}_{\text {mix }}$ ) per crank angle/computational time step as seen in eq. 2 where $N_{C A D}$ is the number of crank angles from $\theta_{i g n}$ and until EVO.

$$
\left.m_{f g}\right|_{B Z}=\left.m_{f g, c y l} \frac{m_{f}}{m_{f, c y l}}\right|_{B Z}
$$

As the share of fresh gas in the cylinder $\left(V^{\prime}\right)$ reduces relative to combustion products during combustion and expansion the mixing rate of subsequent BZ’s is assumed to decrease accordingly by introducing $V^{\prime}$ in eq. 2. Yet, $V^{\prime}$ is constant for each BZ and provided by the share of fresh gas at the crank angle of its formation.

To examine the influence of fresh gas mixing into the BZ's the mixing factor $\beta$ is introduced. $\beta$ has no unit but should reflect the engine speed inversely whereby eq. 2 also considers time. Moreover, $\beta$ acts as a model calibration factor that can be adapted according to a measured exhaust gas $\mathrm{NO}_{\mathrm{x}}$ concentration. In contrast, $m_{f g}, V^{\prime}$ and $N_{C A D}$ are governed by model inputs.

$$
\left.\dot{m}_{m i x}\right|_{B Z}=\left.\frac{\Delta m}{\Delta \theta}\right|_{B Z}=\left.\beta \frac{m_{f g}}{N_{C A D} / \Delta \theta} V^{\prime}\right|_{B Z}
$$

The effect of $\beta$ on BZ temperature and excess air ratio $(\lambda)$ traces is illustrated for selected BZ's $(1,20$ and 40) in Figure 3. By definition; if $\beta=1$ then BZ number 1 (formed at $\theta_{\text {ign }}$ ) is linearly mixed with fresh gas to the trapped/overall excess air ratio $\left(\lambda_{t}\right)$ at EVO (110 CA ATDC). For subsequent BZ's the linear gradient is lower due to the implementation of $V^{\prime}$ in eq. 2 . If $\beta>1$ then BZ number 1 is mixed to $\lambda_{t}$ before EVO and holds this value as seen in the figure. If $\beta<1$ none of the BZ's are mixed fully to $\lambda_{t}$. 
Cylinder gas expansion and fresh gas mixing act to cool the BZ’s. The ideal gas law and conservation of gas enthalpies govern the cooling. The temperature traces are lowered if $\beta$ is increased as shown in Figure 3. The left most point on each trace in the figure represents the simulated stoichiometric flame condition. For all BZ's the flame temperature is $\approx 2500-2600 \mathrm{~K}$. The BZ temperature traces and mixing histories are used subsequently to integrate the chemical reaction rates (of the reaction mechanism) in the BZ's during the expansion stroke. The fresh gas starts being consumed (by the BZ's) when the fuel ignites and the fresh gas is modeled as a single uniform gas zone with a frozen species composition since its peak temperature (at max cylinder pressure) is less than $1000 \mathrm{~K}$ as seen in Figure 3.
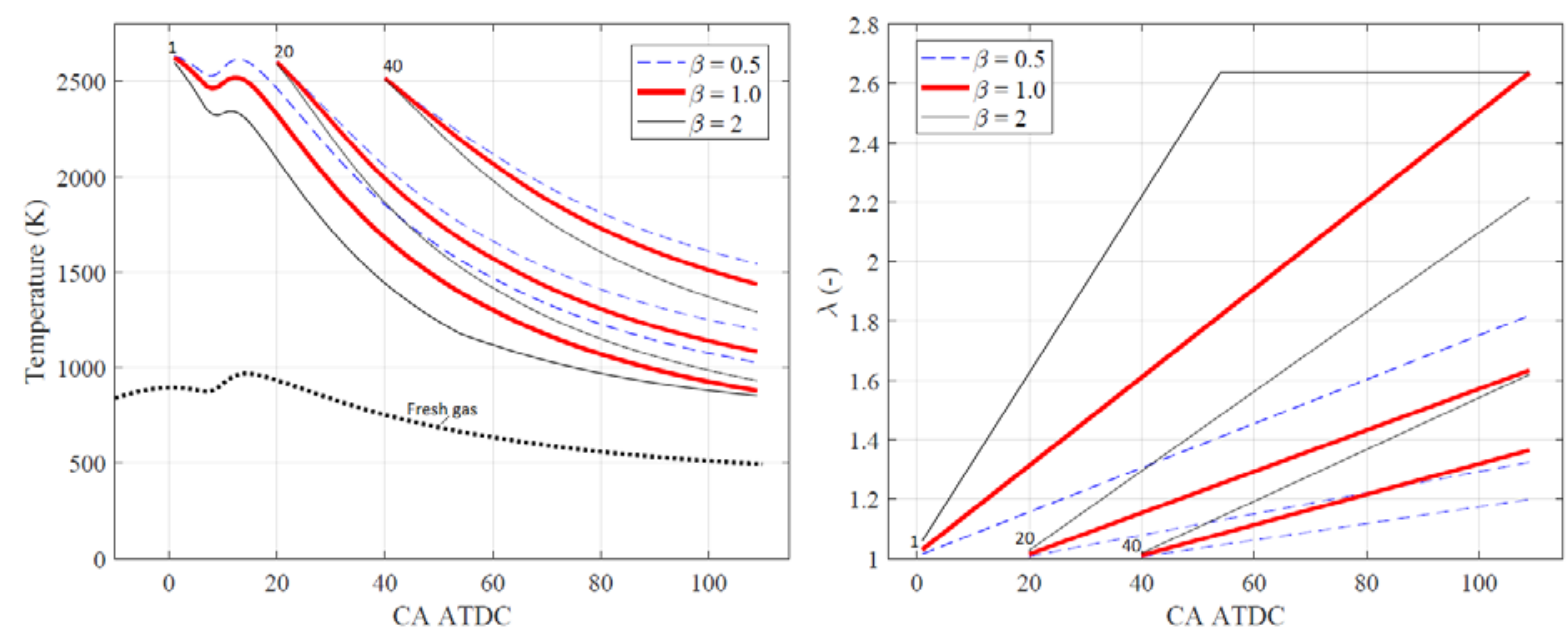

Figure 3. Temperature (also of the fresh gas) and excess air ratio $(\lambda)$ traces of three selected burned zones $(1,20$ and 40) with respect to the crank angle position after top dead center (CA ATDC) and fresh gas mixing intensity ( $\beta$ ). The numbers in the figure refer to the three burned zones. Burned zone number 1 represents the fuel ignition.

\subsection{VAPOR LIQUID EQUILIBRIUM}

The applied $\mathrm{H}_{2} \mathrm{O}-\mathrm{H}_{2} \mathrm{SO}_{4}$ VLE model[12] is used to determine sulfuric acid dew points and deals with an ideal gas phase in equilibrium with a liquid sulfuric acid solution. The saturation (partial) pressure ( $p_{i}$ ) of $\mathrm{H}_{2} \mathrm{O}$ and $\mathrm{H}_{2} \mathrm{SO}_{4}$ are related to the saturation temperature $(T)$ and the liquid sulfuric acid 
strength $\left(c_{a}\right)$ as seen in eq. 3 where subscript " $i$ “ refers to water (w) or acid (a). $\chi_{i}$ is the liquid mole fraction, $\gamma_{i}$ is the activity coefficient and $p_{i}{ }^{0}$ is the vapor pressure of the pure substance and provided in the literature[33,34]. $\gamma_{i}$ is derived from the Non-Random Two Liquid model (NRTL equation) wherein adjustable parameters are fitted to reproduce experimental data of pressure, vapor phase composition and liquid molar enthalpy as cited[12]. The VLE is valid for liquid acid concentrations up to $96 \% \mathrm{~m} / \mathrm{m}$ (in the temperature range from $0-240{ }^{\circ} \mathrm{C}$ ).

$$
p_{i}\left(T, c_{a}\right)=\chi_{i} \gamma_{i} p_{i}^{0}
$$

According to Gibbs phase-rule, the $\mathrm{H}_{2} \mathrm{O}-\mathrm{H}_{2} \mathrm{SO}_{4}$ VLE provides two degrees of freedom and the saturation temperature that defines the sulfuric acid dew point temperature $\left(T_{a, d}\right)$ can be found iteratively if $p_{w}$ and $p_{a}$ are known. The dew point of pure water vapor $\left(T_{w, d}\right)$ is lower than $\left(T_{a, d}\right)$ and determined by $p_{w}{ }^{0}$ only.

\subsection{CONDENSATION MODEL}

Condensation of $\mathrm{H}_{2} \mathrm{O}$ and $\mathrm{H}_{2} \mathrm{SO}_{4}$ is modeled on the basis of a homogenous cylinder gas mixture. I.e. the multiple gas species in the BZ's and the fresh gas are uniformly spread throughout the instant cylinder volume and gas properties are evaluated at the mean composition and temperature. The condensable species diffuse from the bulk cylinder gas to the liner surface, or more exactly, to the gas-liquid interphase on top of the very thin liquid condensate film that develops on the liner surface. Condensation/phase transformation takes place at the gas liquid interphase only. I.e. supersaturation within the gas phase thermal boundary (realized by the large temperature difference between the bulk gas and the liner surface) is neglected. 
The condensing (or evaporative) flux $\left(g_{i}\right)$ in eq. 4 is coupled to the convective mass transfer coefficient $\left(h_{m, i}\right)$ and the partial pressure difference $\left(\Delta p_{i}=p_{i, B}-p_{i, S}\right)$ between the bulk gas and the gas-liquid interphase. The bulk gas pressure of $\mathrm{H}_{2} \mathrm{O}$ and $\mathrm{H}_{2} \mathrm{SO}_{4}\left(p_{i, B}\right)$ relative to the crank angle position are outputs generated by the engine model (section 2.1). Transition from vapor to liquid phase is not rate limiting[26] and the surface pressure $\left(p_{i, S}\right)$ in the gas-liquid interphase is provided by the VLE (section 2.2).

$$
g_{i}=h_{m, i}\left(p_{i, B}-p_{i, S}\right) \frac{1}{R_{i} T_{g}}
$$

The gas dew points at each crank angle (evaluated from $p_{i, B}$ ) are used to define two condensation cases:

In condensation case 1 the liner surface temperature $\left(T_{S}\right)$ is lower than $\left(T_{a, d}\right)$ but higher than $\left(T_{w, d}\right)$. In this situation the condensing water represents an infinitesimal share of the $\mathrm{H}_{2} \mathrm{O}$ content in the bulk cylinder gas since the difference between $p_{w, B}$ and $p_{w, S}$ is very small. The equality is used together with eq. 3 (concerning $\mathrm{H}_{2} \mathrm{O}$ properties) to determine the condensing acid strength in the gas liquid interphase $\left(c_{a}\right)$ through an iteratively procedure where $p_{w}=p_{w, B}$ and $T=T_{S}$ are used as input. By applying the calculated value of $c_{a}$ and $T=T_{S}$ to eq. 3 (concerning $\mathrm{H}_{2} \mathrm{SO}_{4}$ properties) the $\mathrm{H}_{2} \mathrm{SO}_{4}$ surface pressure $\left(p_{a, S}\right)$ needed to calculate $g_{a}$ (eq. 4) is determined. The VLE in the gas liquid interphase requires that the flux of water in condensation case is: $g_{w}=g_{a} \frac{1-c_{a}}{c_{a}}$.

In condensation case $2, T_{S}$ is lower than $T_{w, d}$ and the condensing acid is highly diluted by water since $\Delta p_{w}>\Delta p_{a}$. Hence, $c_{a}$ and $p_{a, S}$ are practically zero which means that $p_{w, S}$ is equivalent to the saturation pressure of pure $\mathrm{H}_{2} \mathrm{O}$ vapor at $T=T_{S}$. 
A coupling between convective heat and mass transfer is shown to exist if the functional form of the thermal and the species boundary layer is the same[35]. Fundamentally, the dimensionless temperature and species gradient at the surface $N u=f(R e, P r)$ and $S h=f(R e, S c)$ respectively are linked as shown in eq. 5 where $n$ is a turbulent exponent of less than one.

$$
\frac{N u}{\operatorname{Pr}^{n}}=\frac{S h}{S c^{n}}
$$

The heat and mass transfer analogy is suited for low mass transfer rates i.e. when the driving force $\Delta p_{i}$ is moderate[36] which applies for both $\mathrm{H}_{2} \mathrm{O}$ and $\mathrm{H}_{2} \mathrm{SO}_{4}$ in the present case. In eq. 6 the analogy is rewritten and expressed as the ratio between the convective heat $\left(h_{c}\right)$ and the convective mass transfer coefficient $\left(h_{m, i}\right)$ where the Lewis number, $L e_{i}=\frac{k_{g}}{\rho_{g} c_{p, g} \mathcal{D}_{i, g}}$ describes the ratio of thermal and mass diffusivity $\left(D_{i, g}\right)$. In this work $\mathcal{D}_{i, g}$ is approximated using the binary diffusion coefficient of $\mathrm{H}_{2} \mathrm{O}$ or $\mathrm{H}_{2} \mathrm{SO}_{4}$ in a large excess of air. At atmospheric pressure $\mathcal{D}_{a, g}=0.08 \mathrm{~cm}^{2} \mathrm{~s}^{-1}$ at $296 \mathrm{~K}$ [37] and $\mathcal{D}_{w, g}=0.260 \mathrm{~cm}^{2} \mathrm{~s}^{-1}$ at $293 \mathrm{~K}[38]$. The effect of gas temperature and pressure on the $\mathcal{D}_{i, g}$ coefficients can be approximated using $\mathcal{D}_{i, g} \propto T^{3 / 2} / p$ [39].

$$
\frac{h_{c}}{h_{m, i}}=\rho_{g} c_{p, g} L e_{i}^{1-n}
$$

During condensation a very thin liquid film forms on the liner surface. Heat is conducted through the film and is composed by convective heat $\left(H_{c}\right)$ plus latent heat $\left(H_{l}\right)$ that is liberated by the condensing species. In a diesel process $H_{c}>H_{l}$ so the overall heat transfer is by far governed by $H_{c}$. The convective heat transfer coefficient $\left(h_{c}\right)$ is determined using Woschnis correlation[25] wherein empirical coefficients are adjusted to simulate the heat loss of the modeled engine. The correlation provides the mean $h_{c}$-value at each crank angle position that this closely coupled to the cylinder pressure (Fig. 1). 
It can be shown that the orientation of the reversible reaction R.1 is highly orientated towards the left hand side for the BZ-temperature traces. $\mathrm{H}_{2} \mathrm{SO}_{4}$ does therefore not form in the hot cylinder gasses. Yet, when modeling sulfuric acid condensation it makes sense to lump $\mathrm{SO}_{3}$ and $\mathrm{H}_{2} \mathrm{SO}_{4}$ of the bulk gas since R.1 is very fast and highly orientated to the right hand side at temperatures equivalent to $T_{S}$. Very close to the liner surface (just prior to condensation) $\mathrm{SO}_{3}$ from the bulk cylinder gas is thus assumed to convert fully to gaseous $\mathrm{H}_{2} \mathrm{SO}_{4}$ with readily available water vapor. I.e. $p_{a, B}$ and therefore also $T_{a, d}$ in the condensation model is essentially coupled to the $\mathrm{SO}_{3}$ bulk gas pressure.

$$
\mathrm{H}_{2} \mathrm{O}(g)+\mathrm{SO}_{3}(g) \Leftrightarrow \mathrm{H}_{2} \mathrm{SO}_{4}(g)
$$

\section{RESULTS}

Figure 4 shows calculated cylinder gas concentrations of $\mathrm{SO}_{3}$ during the expansion stroke at different fresh gas mixing intensities expressed by $\beta$ where $\beta_{\text {cal }} \approx 0.75$ represents a calibrated $\beta$-value. The widespread $\beta$-range is applied in order to stimulate especially the effect of gas mixing on sulfuric acid condensation. For simplicity $\beta$ is assumed to have no influence on the fuel burn rate and pressure history. In the initial stage of combustion the fuel sulfur is converted to $\mathrm{SO}_{2}$ on a time scale comparable to the fuel oxidation reactions[40]. $\mathrm{SO}_{3}$ forms moderately (at the expense of $\mathrm{SO}_{2}$ ) during the expansion stroke but the governing reactions freeze as the gas cools and the concentration tends to stabilize as illustrated in the figure. The fraction of the fuel sulfur that is converted to $\mathrm{SO}_{3}$ $\left(\varepsilon=\frac{\left[\mathrm{SO}_{3}\right]}{\left[\mathrm{SO}_{2}\right]+\left[\mathrm{SO}_{3}\right]}\right)$ illustrated in the figure shows that $\epsilon$ accounts for a few percent at EVO and elevated gas mixing promotes $\mathrm{SO}_{3}$ formation. The calculated $\mathrm{SO}_{3}$-fraction falls within the reported range[1,2] and scales closely with $\beta^{4 / 9}$. 

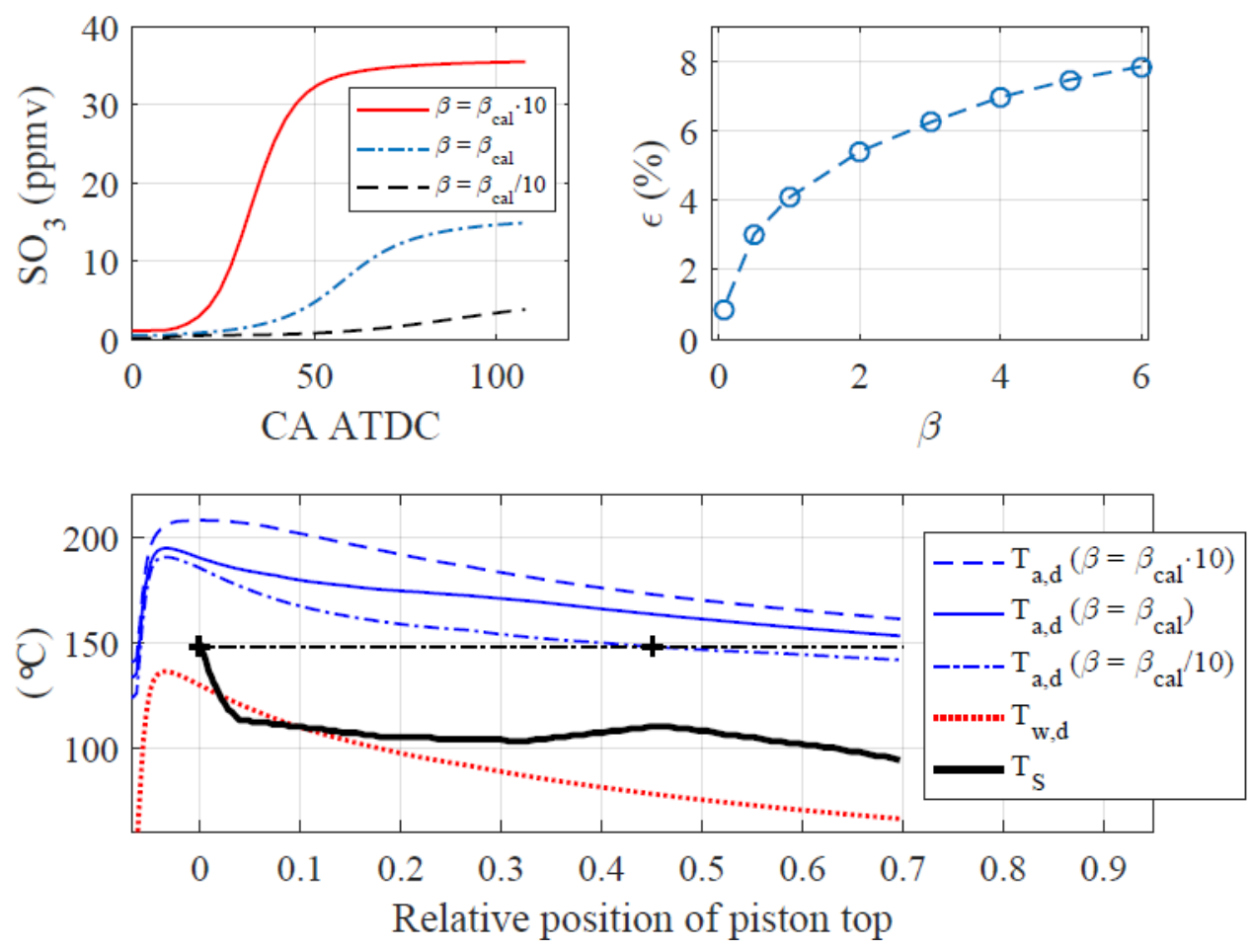

Figure 4. Upper left figure: Overall $\mathrm{SO}_{3}$ concentration in the cylinder gas vs. the crank angle position after top dead center (CA ATDC) and fresh gas mixing intensity $(\beta)$ that is . Upper right figure: The fraction of the fuel sulfur that is converted to $\mathrm{SO}_{3}(\varepsilon)$ at EVO versus $\beta$. Lower figure: Cylinder liner surface temperature profile $\left(T_{S}\right)$ and dew point traces of $\mathrm{H}_{2} \mathrm{O}\left(T_{w, d}\right)$ and $\mathrm{H}_{2} \mathrm{SO}_{4}\left(T_{a, d}\right)$ versus $\beta$. The black dash-dotted line illustrates that the temperature in the very top of the liner exceeds $T_{a, d}$ during the expansion stroke when $\beta=\beta_{c a l} / 10$.

The liner surface temperature $T_{S}$ in Figure 4 is a realistic model temperature profile at $25 \%$ load. For the computations it is split into numerous ring segments of fixed temperatures. On each segment condensation or evaporation may occur according to section 2.3. Moreover, trace amounts of $\mathrm{H}_{2} \mathrm{O}$ and $\mathrm{H}_{2} \mathrm{SO}_{4}$ vapor in the top land crevice is disregarded. Condensation is therefore only modeled on the share of the liner surface that is in contact with a moving piston ring and a liner segment is only exposed to the cylinder gas once the piston top has passed it during the expansion stroke.

In Figure 4 dew point traces $\left(T_{i, d}\right)$ resulting from the widespread $\beta$-range are plotted against the position of the piston top that is normalized by the engine stroke. When the fuel ignites the top is 
positioned above the sliding part of the liner at a relative position of less than zero. At the same time $T_{a, d}$ and $T_{w, d}$ increase sharply along with the rapid pressure rise. $T_{a, d}$ is coupled to the $\mathrm{SO}_{3}$ pressure and thereby to $\beta$. With the applied $\beta$-values the trace is altered approximately $30-40{ }^{\circ} \mathrm{C}$ and is generally exceeding $T_{S}$. Except in the very top of the liner at $\beta=\beta_{\text {cal }} / 10$ where condensation is followed by evaporation at the point where the black dash-dotted line intersects with $T_{a, d}$. Referring to $\beta_{\text {cal }}$ it seems however most likely that sulfuric acid will condense continuously on the exposed liner surface until EVO. Formation of $\mathrm{H}_{2} \mathrm{O}$ vapor is independent of $\beta$ and reflects the fuel burn rate so the $T_{w, d}$ trace therefore applies to all $\beta$-values. $T_{w, d}$ peaks during combustion and condensation of "pure water" is confined to the top of the liner where $T_{w, d}$ exceeds $T_{S}$.

To deal with the unknown gas turbulence intensity the mass transfer is modeled at laminar and turbulent conditions by setting $n$ (eq. 6) to $1 / 3$ and 1 respectively. In Figure $5 G_{a}$ represents the integrated mass of deposited sulfuric acid on the cylinder liner at EVO. The order is a few milligrams and mirrors the $\mathrm{SO}_{3}$-trace with respect to $\beta$ in Figure 4 . At $\beta=\beta_{\text {cal }}$ the laminar and the turbulent mass transfer provides that $G_{a}$ is $0.6 \mathrm{mg}$ and $1.2 \mathrm{mg}$ respectively. Most of the acid condense irrespective of $\beta$ on the upper half of the liner as illustrated by the relative mass distribution $\left(G^{\prime \prime}{ }_{a}\right)$. I.e. on the liner segments that are exposed to the cylinder gas for the longest time, the highest $\mathrm{SO}_{3}$ pressures and heat transfer rates.

Although the $\mathrm{H}_{2} \mathrm{O}$ pressure trace is independent of $\beta, g_{w}$ must like $g_{a}$ alter with $\beta$ according to the $c_{a}$-relation in condensation case 1 as described earlier. For the applied surface temperature profile the deposition of water $\left(G_{w}\right)$ on the liner surface is comparable to $G_{a}$ since the liner area where $T_{s}<T_{w, d}$ is limited. However, within this area nearly "pure water" is condensing and explains the peaks of the water mass distribution $\left(G^{\prime \prime}{ }_{w}\right)$ in Figure 5. 

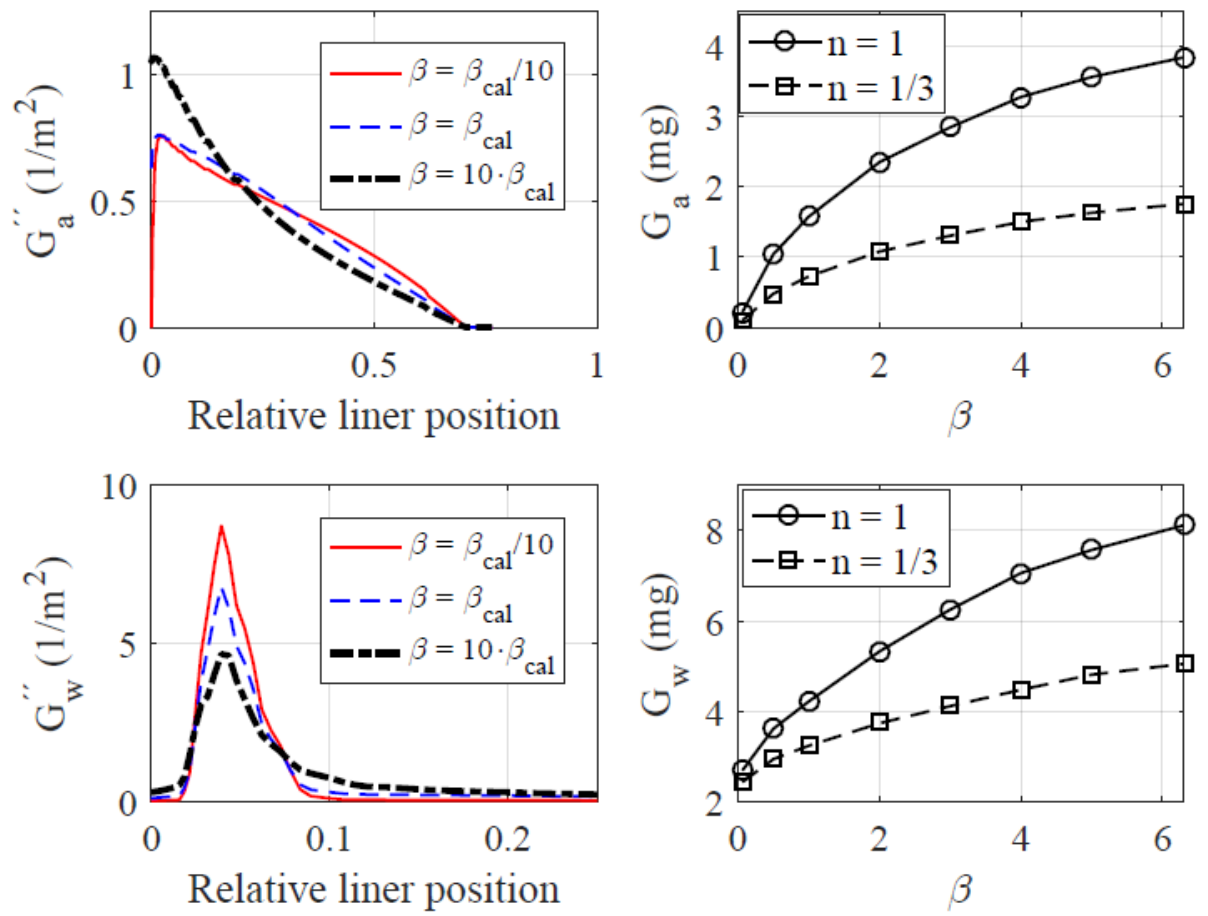

Figure 5. Right figures: Deposited sulfuric acid and water ( $G_{a}$ and $G_{w}$ respectively) on the liner at EVO vs. gas turbulence $(n)$ and fresh gas mixing intensity $(\beta)$. Left figures: Distribution of sulfuric and water $\left(G_{a}{ }^{\prime \prime}\right.$ and $\left.G_{w}{ }^{\prime \prime}\right)$ on the liner at EVO with respect to $\beta$ (normalized by $G_{a}$ and $G_{w}$ respectively).

In-house measurements have shown that $\epsilon$ of the exhaust gas is $\approx 4 \%$ at $25 \%$ engine load and agrees fairly with the modeled $\varepsilon$-value at $\beta_{c a l}$ (Figure 4). Throughout the rest of the paper results therefore apply to $\beta=\beta_{\text {cal }}$.

The engine cylinders are charged with cooled and pressurized ambient air at a humidity $(\varphi)$ determined by the ambient humidity, charge pressure and temperature. Saturated charge air conditions $(\varphi=1)$ are frequent at sea and it significantly increases the $\mathrm{H}_{2} \mathrm{O}$ concentration/pressure of the cylinder gas as can be seen in Figure 6. Moreover the share of the liner that is subject to "pure water" condensation $\left(T_{S}<T_{w, d}\right)$ increases with $\varphi$. Consequently at $\varphi=1 G_{w}$ is about 20 times higher compared to the case with dry air ( $\varphi=0$ ) as illustrated. Throughout the cycle $L e_{w} \approx 1$ and 
$G_{w}$ is rather determined by $\Delta p_{w}$ (eq. 4 ) than the turbulence intensity $(n) . G_{a}$ is practically constant as the modeled $\mathrm{SO}_{3}$ concentration is highly independent of $\varphi$ as illustrated.
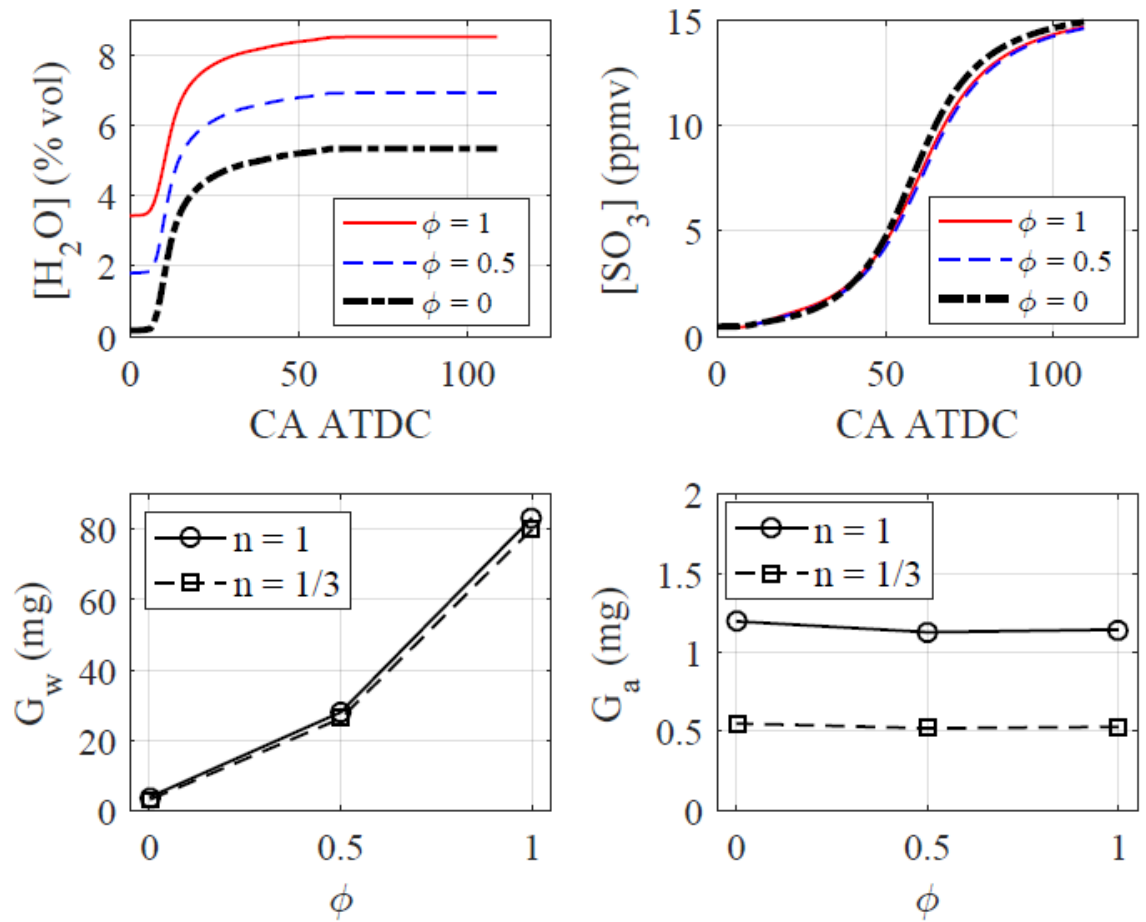

Figure 6. Upper figures: Cylinder gas concentrations of $\mathrm{H}_{2} \mathrm{O}$ and $\mathrm{SO}_{3}$ vs. the relative humidity of the charge air $(\varphi)$ and the crank angle position after top dead center (CA ATDC). Lower figures: Deposited sulfuric acid and water ( $G_{a}$ and $G_{w}$ respectively) on the liner at EVO vs. $\varphi$ and gas turbulence intensity $(n)$.

In Figure 7 modeling variations give rise to the three realistic liner temperature profiles $T_{S, l o w}, T_{S, \text { mid }}$ and $T_{S, \text { high }}$ that cover normal temperature variations at $25 \%$ engine load. The $T_{S}$-profile used so far is their average and the calculated results shown in the figure apply to $0.5 \% \mathrm{~m} / \mathrm{m}$ fuel sulfur. As illustrated with $T_{S, h i g h}$ the temperature in the very top of the liner may exceed $T_{a, d}$ (during the expansion stroke) at the point where it intersects with the dash-dotted line. At this point condensation is replaced by evaporation. The evaporative rates are however comparably slow and the sharp 
negative $T_{S}$-gradient in the top of the liner provides that $T_{a, d}$ is exceeding $T_{S}$ for the major liner surface. Therefore $G_{a}$ is only slightly reducing with the level of $T_{s}$ as seen in the figure and for higher fuel sulfur contents the differences in $G_{a}$ will vanish. This suggests that within the normal range of liner temperature profiles $G_{a}$ is not affected by the surface temperature. On the other hand since the area of "pure water" condensation $\left(T_{S}<T_{w, d}\right)$ alter significantly with $T_{s}$ as seen in the figure $G_{w}$ is very sensitive to the applied temperature profile. Under the given conditions $G_{w}$ is about 40 times higher at $T_{S, l o w}$ compared to $T_{S, \text { high }}$ as illustrated in the figure.
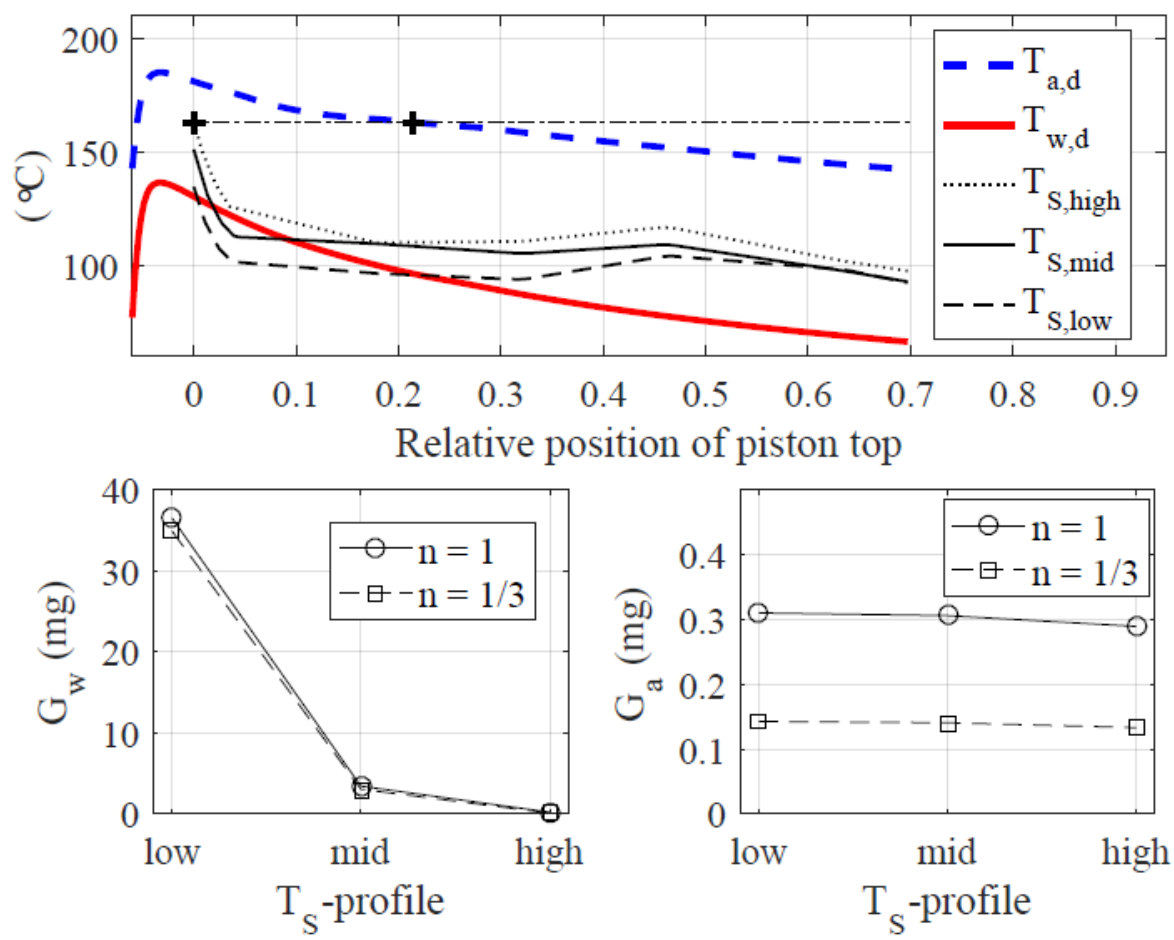

Figure 7. Upper figure: Liner surface temperature profiles $\left(T_{S, l o w}, T_{S, \text { mid }}\right.$ and $\left.T_{S, \text { high }}\right)$ and dew point traces of $\mathrm{H}_{2} \mathrm{O}$ and $\mathrm{H}_{2} \mathrm{SO}_{4}\left(T_{w, d}\right.$ and $T_{a, d}$ respectively) during the expansion stroke (dry charge air) at $0.5 \% \mathrm{~m} / \mathrm{m}$ fuel sulfur. The liner is only exposed to the cylinder gas once the relative position of the piston top is $>0$. Lower figures: Deposited sulfuric acid and water ( $G_{a}$ and $G_{w}$ respectively) on the liner at EVO vs. $T_{S}$-profile. The dash-dotted line illustrates that the temperature in the very top of the liner exceeds $T_{a, d}$ during the expansion stroke at $T_{S, h i g h}$. 
Since the beginning of 2012 the sulfur limit of heavy fuel oils has been $3.5 \% \mathrm{~m} / \mathrm{m}$ as set by the International Maritime Organization. However fuels with a higher sulfur content are accepted when e.g. exhaust gas scrubbers are installed onboard the vessel to remove sulfur oxides from the exhaust gas. The role of the fuel sulfur in terms of condensation is studied with the assumption that the fuel burn rate, heating value and $\mathrm{H}_{2} \mathrm{O}$ concentration is the same irrespective of the sulfur content. With the engine model it can then be shown that $\varepsilon$ of the exhaust gas is largely the same when the sulfur content is between $0.5 \% \mathrm{~m} / \mathrm{m}$ and $5 \% \mathrm{~m} / \mathrm{m}$. It then follows that the $\mathrm{SO}_{3}$ concentration in the exhaust gas increases linearly with the sulfur content. Yet, at the same time the $T_{a, d}$-trace is not highly affected as shown in Figure 8. Like in Figure 7, $T_{S}$ can exceed $T_{a, d}$ in the very top of the liner but with very little influence on $G_{a}$. Thus, as $T_{a, d}$ is generally exceeding $T_{S}$, the results in Figure 8 suggests that the deposition of acid follows the response of $\mathrm{SO}_{3}$ and increases linearly with the sulfur content as illustrated by $G_{a}$ in the figure.
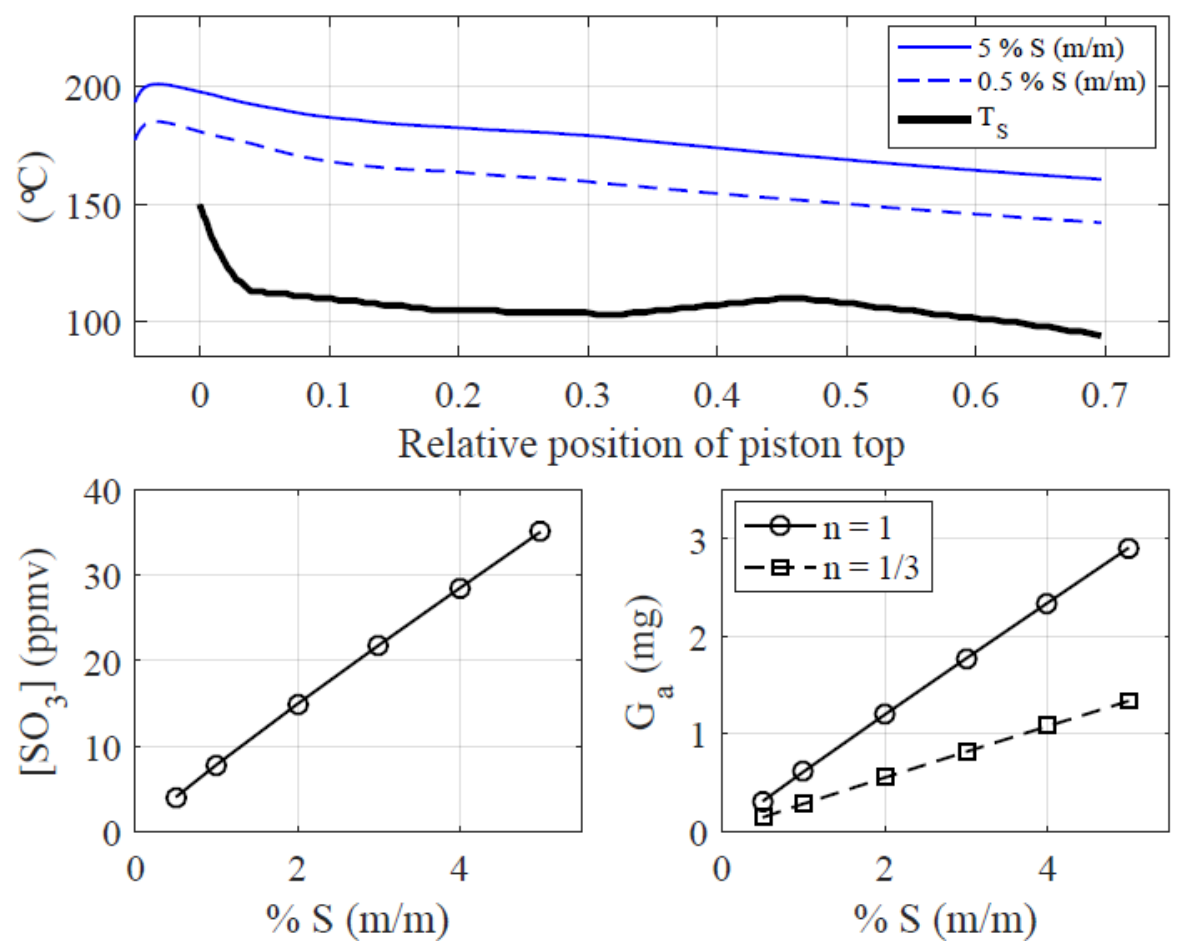
Figure 8. Upper figure: Liner surface temperature $\left(T_{S}\right)$ and $\mathrm{H}_{2} \mathrm{SO}_{4}$ dew points $\left(T_{a, d}\right)$ vs. fuel sulfur content (\% $\left.\mathrm{S} \mathrm{m} / \mathrm{m}\right)$ during the expansion stroke (dry charge air). The liner is only exposed to the cylinder gas once the relative position of the piston top is $>0$. Lower figures: $\mathrm{SO}_{3}$ concentration of the cylinder gas and deposited sulfuric acid $\left(G_{a}\right)$ on the cylinder liner at EVO vs. fuel sulfur content.

\section{DISCUSSION}

When modeling the combined condensation of sulfuric acid and water on the cylinder liner of a large two-stroke marine diesel engine the applied assumption of a homogenous cylinder gas mixture is not entirely true. In reality the heterogeneous composition combined with irregular turbulence intensities of the mixing controlled combustion process challenge the modeled dew points and condensation rates. In addition gaseous $\mathrm{H}_{2} \mathrm{SO}_{4}$ may undergo supersaturation and form acid mists (due to abrupt cooling from the liner) in the thermal boundary layer at the gas-liquid interphase. The applied heat and mass transfer analogy does not account for mist formation and could overestimate the deposition of sulfuric acid as the mist tends to follow the gas stream lines[22]. Possible interferences of $\mathrm{H}_{2} \mathrm{SO}_{4}$ interactions with fuel impurities or particulate matter might also inhibit deposition. Nevertheless several trends of condensation of sulfuric acid and water can be retrieved:

The liner temperature is generally lower than the sulfuric acid dew point. Acid appears therefore to condense continuously on the share of the liner surface that is exposed to the cylinder gas during the expansion stroke. As a consequence, the deposition will increase with the fuel sulfur content through elevated $\mathrm{SO}_{3}$ concentrations. Experimental work performed with a heavy duty engine[1] shows that more fuel sulfur is converted to $\mathrm{SO}_{3}$ if the operating pressure increases. The deposition of acid is therefore expected to increase accordingly. The present work finds that most of the acid will condense on the upper part of the liner. In the top of the liner the acid is diluted with condensing water and the extend of dilution is governed by the liner temperature and charge air humidity. 
In practice corrosion is known to be most severe in the top of the liner. More specifically around the positon of the piston rings at TDC. Different electrochemical reactions may be involved when the cast iron liner is corroding. Sulfuric acid can corrode the liner through a reaction where hydrogen is replaced[14] but without the electrochemical effect of water reaction R.2 is quite slow.

$$
\mathrm{Fe}(\mathrm{s})+\mathrm{H}_{2} \mathrm{SO}_{4}(l)+\mathrm{H}_{2} \mathrm{O}(l) \rightarrow \mathrm{H}_{2}(g)+\mathrm{FeSO}_{4}(s)+\mathrm{H}_{2} \mathrm{O}(l)
$$

It is accepted that aqueous solutions of sulfuric acid is more aggressive than concentrated acid[18,41]. For corrosion caused by exhaust gasses it is also mentioned that the sulfur content combined with the onset of pure water condensation is critical[42]. Corrosion from pure water is comparably slow. However the moist air in coastal regions is known to promote corrosion through a comparably high electric conductivity of the moisture that is explained by the presence of sodium chlorine in the sea water.

$\mathrm{SO}_{2}$ in the cylinder gas may promote corrosion by forming sulfurous acid[14] if it dissolves in condensed water as illustrated in the overall reaction (R.3). Yet, the significance of $\mathrm{SO}_{2}$-corrosion is questionable as the sulfurous acid is a weak acid and since the $\mathrm{SO}_{2}$ solubility[17] is very low at the applied liner temperatures.

$$
\mathrm{SO}_{2}(g)+2 \mathrm{H}_{2} \mathrm{O}(\mathrm{l})+3 \mathrm{Fe}(\mathrm{s}) \rightarrow \mathrm{FeS}(\mathrm{s})+2 \mathrm{Fe}(\mathrm{OH})_{2}(\mathrm{~s})
$$




\section{CONCLUSION}

Condensation of sulfuric acid and water on the cylinder liner of a large two-stroke marine diesel engine is modeled at a low power output matching modern service engines. A phenomenological 0D engine model involving a detailed gas phase reaction mechanism is combined with $\mathrm{H}_{2} \mathrm{O}-\mathrm{H}_{2} \mathrm{SO}_{4}$ vapor liquid equilibrium to compute dew points. Condensation is modeled through coupled heat and mass transfer by assuming a homogenous cylinder gas mixture and by implementing realistic model liner temperature traces. Deposition of liquid sulfuric acid is a few milligrams on the liner every cycle and varies linearly with the fuel sulfur content. Most acid condenses on the upper part of the liner. Pure water tends to condense on the top of the liner and may highly dilute the acid if the charge air is humidified or if the liner temperature is in the low range of the normal liner temperature range.

\section{ACKNOWLEDGMENT}

The authors would like to thank the Innovation Fund Denmark for their contribution to project Sulcor.

\section{AUTHOR INFORMATION}

*E-mail: rco@mek.dtu.dk 


\begin{tabular}{|c|c|c|}
\hline Symbol & & Unit \\
\hline$c_{a}$ & Liquid/condensing acid strength & $\mathrm{kg} / \mathrm{kg}$ \\
\hline$c_{p, q}$ & Specific heat capacity of cylinder gas & $\mathrm{J} / \mathrm{kg}-\mathrm{K}$ \\
\hline$g_{i}$ & Mass flux of gaseous $\mathrm{H}_{2} \mathrm{SO}_{4}$ or $\mathrm{H}_{2} \mathrm{O}$ & $\mathrm{kg} / \mathrm{m}^{2}-\mathrm{s}$ \\
\hline$G_{i}$ & Accumulated liquid $\mathrm{H}_{2} \mathrm{SO}_{4}$ or $\mathrm{H}_{2} \mathrm{O}$ on the liner at exhaust valve opening & $\mathrm{mg}$ \\
\hline$G^{\prime \prime}{ }_{i}$ & Distribution of liquid $\mathrm{H}_{2} \mathrm{SO}_{4}$ or $\mathrm{H}_{2} \mathrm{O}$ on the liner at exhaust valve opening & $1 / \mathrm{m}^{2}$ \\
\hline$h_{c}$ & Convective heat transfer coefficient & $\mathrm{W} / \mathrm{m}^{2}-\mathrm{K}$ \\
\hline$h_{m i}$ & Convective mass transfer coefficient of gaseous $\mathrm{H}_{2} \mathrm{SO}_{4}$ or $\mathrm{H}_{2} \mathrm{O}$ & $\mathrm{m} / \mathrm{s}$ \\
\hline$k_{q}$ & Thermal conductivity of cylinder gas & $\mathrm{W} / \mathrm{m}-\mathrm{K}$ \\
\hline$L e_{i}$ & Lewis number of $\mathrm{H}_{2} \mathrm{SO}_{4}$ or $\mathrm{H}_{2} \mathrm{O}$ & - \\
\hline$m_{f}$ & Fuel mass in a burned zone & $\mathrm{kg}$ \\
\hline$m_{f, c y l}$ & Fuel mass injected to the cylinder every cycle & $\mathrm{kg}$ \\
\hline$m_{f g}$ & Fresh gas threshold of a burned zone & $\mathrm{kg}$ \\
\hline$m_{f g, c y l}$ & Trapped fresh gas in the cylinder when the gas compression starts & $\mathrm{kg}$ \\
\hline$\dot{m}_{\text {mix }}$ & Mixing rate of fresh gas into a burned zone per crank angle degree & $\mathrm{kg} / \mathrm{CAD}$ \\
\hline$n$ & Gas turbulence exponent & - \\
\hline$N_{C A D}$ & Number of crank angle degrees between $\theta_{\text {ign }}$ and exhaust valve opening & CAD \\
\hline $\mathrm{Nu}$ & Nusselt number & - \\
\hline$p_{i}$ & Partial pressure of $\mathrm{H}_{2} \mathrm{SO}_{4}$ or $\mathrm{H}_{2} \mathrm{O}$ & $\mathrm{Pa}$ \\
\hline$p_{i, B}$ & Partial pressure of $\mathrm{H}_{2} \mathrm{SO}_{4}$ or $\mathrm{H}_{2} \mathrm{O}$ in the bulk/cylinder gas & $\mathrm{Pa}$ \\
\hline$p_{i, S}$ & Partial pressure of $\mathrm{H}_{2} \mathrm{SO}_{4}$ or $\mathrm{H}_{2} \mathrm{O}$ at the gas-liquid interface & $\mathrm{Pa}$ \\
\hline$p_{i}^{0}$ & Vapor pressure of pure $\mathrm{H}_{2} \mathrm{SO}_{4}$ or $\mathrm{H}_{2} \mathrm{O}$ & $\mathrm{Pa}$ \\
\hline $\operatorname{Pr}$ & Prandtl number & - \\
\hline$R e$ & Reynolds number & - \\
\hline$R_{i}$ & Specific gas constant of $\mathrm{H}_{2} \mathrm{SO}_{4}$ or $\mathrm{H}_{2} \mathrm{O}$ & $\mathrm{J} / \mathrm{kg}-\mathrm{K}$ \\
\hline$T$ & Saturation temperature & $\mathrm{K}$ \\
\hline$T_{q}$ & Cylinder gas temperature & $\mathrm{K}$ \\
\hline$T_{S}$ & Temperature of liner surface & ${ }^{\circ} \mathrm{C}$ \\
\hline$T_{i, d}$ & Dew point of sulfuric acid or pure water vapor & ${ }^{\circ} \mathrm{C}$ \\
\hline$S c$ & Schmidt number & - \\
\hline$S h$ & Sherwood number & - \\
\hline$V^{\prime}$ & Share of fresh gas in the engine cylinder & $\mathrm{m}^{3} / \mathrm{m}^{3}$ \\
\hline$\chi_{i}$ & Mole fraction of $\mathrm{H}_{2} \mathrm{SO}_{4}$ or $\mathrm{H}_{2} \mathrm{O}$ (in aqueous acid solution) & mole/mole \\
\hline$\beta$ & Fresh gas mixing factor & - \\
\hline$\beta_{c a l}$ & Calibrated fresh gas mixing factor & - \\
\hline$\gamma_{i}$ & Activity coefficient of $\mathrm{H}_{2} \mathrm{SO}_{4}$ or $\mathrm{H}_{2} \mathrm{O}$ (in aqueous acid solution) & - \\
\hline $\mathcal{D}_{i, g}$ & Binary mass diffusion coefficient of gaseous $\mathrm{H}_{2} \mathrm{SO}_{4}$ or $\mathrm{H}_{2} \mathrm{O}$ in air & $\mathrm{m}^{2} / \mathrm{s}$ \\
\hline$\theta_{i g n}$ & Crank angle degree where the fuel ignites & CAD \\
\hline$\Delta \theta$ & Engine model computational step & CAD \\
\hline$\lambda$ & Excess air ratio & $\mathrm{kg}_{\text {air }} / \mathrm{kg}_{\text {fuel }}$ \\
\hline$\lambda_{t}$ & Trapped excess air ratio & $\mathrm{kg}_{\text {air }} / \mathrm{kg}_{\text {fuel }}$ \\
\hline$\rho_{g}$ & Density of cylinder gas & $\mathrm{kg}_{\text {air }} / \mathrm{kg}_{\text {fuel }}$ \\
\hline$\varphi$ & Relative humidity of charge air & $\mathrm{Pa} / \mathrm{Pa}$ \\
\hline
\end{tabular}




\section{REFERENCES}

1. Cordtz, R., Schramm, J., and Rabe, R., "Investigating SO3 Formation from the Combustion of Heavy Fuel Oil in a Four-Stroke Medium-Speed Test Engine,” Energy and Fuels 27(10):6279-6286, 2013.

2. $\quad$ Engel, P.K., Thompson, R.E., and Silvestrinin, R., "Corrosion and Fouling Potential in Diesel Exhausts,” Mech. Eng. 101(6):598-606, 1979.

3. Cordtz, R., Schramm, J., Andreasen, A., Eskildsen, S.S., and Mayer, S., "Modeling the distribution of sulfur compounds in a large two stroke diesel engine," Energy and Fuels 27(3):1652-1660, 2013.

4. $\quad$ Reiner, T. and Arnold, F., "Laboratory Investigations of Gaseous Sulfuric-Acid Formations via $\mathrm{SO} 3+\mathrm{H} 2 \mathrm{O}+\mathrm{M}=>\mathrm{H} 2 \mathrm{SO} 4+\mathrm{M}$ : Measurements of the Rate-Constant and Product Identification,” J. Chem. Phys. 101(9):7399-7407, 1994.

5. Okkes, A.G., "Get Acid Dew-Point of Flue-Gas,” Hydrocarb. Process. 66(7):53-55, 1987.

6. Verhoff, F.H. and Banchero, J.T., "Predicting Dew Points of Flue Gases,” Chem. Eng. Prog. 70(8):71-72, 1974.

7. Abel, E., “The Vapour-Phase above the System Sulphuric Acid-Water,” J. Phys. Chem. a 50:260-283, 1946.

8. Greenewalt, C.H., "Partial Pressure of Water out of Aqueous Solutions of Sulfuric Acid," Ind. Eng. Chem. 17:522-523, 1925.

9. Gmitro, J.I. and Vermeulen, T., "Vapor-Liquid Equilibria for Aqueous Sulfuric Acid,” A I Ch E J. 10 No 5:740-746, 1964.

10. Wilson, R.W. and Stein, F.P., "Correlation of Sulfuric Acid-Water Partial Pressures,” Fluid Phase Equilib. 53:279-288, 1989.

11. Pessoa, F.L.P., Siqueira Campos, C.E.P., and Uller, A.M.C., "Calculation of Vapor-Liquid Equilibria in Aqueous Sulfuric Acid Solutions using the UNIQUAC Equation in the whole Concentration Range,” Chem. Eng. Sci. 61(15):5170-5175, 2006, doi:10.1016/j.ces.2006.03.026.

12. Bosen, A. and Engels, H., "Description of the Phase Equilibrium of Sulfuric Acid with the NRTL Equation and a Solvation Model in a wide Concentration and Temperature range," Fluid Phase Equilib. 43(2-3):213-230, 1988, doi:10.1016/0378-3812(88)87008-0.

13. Schramm, J., Henningsen, S., and Sorenson, S., "Modeling of Corrosion of Cylinder Liner in Diesel Engines Caused by Sulphur in the Diesel Fuel,” SAE 940818, 1994.

14. Neageli, D.W. and Marbach, H.W., "Role of Sulfur Oxides in Wear and Deposit Formation in Army Diesel Engines.," San Antonio, Texas, 1988.

15. Nagaki, H. and Korematsu, K., "Effect of Sulfur Dioxide Added to Induction Air on Wear of Diesel Engine,” SAE 930994, 1994.

16. Costa, D.L. and Underhill, D., "Solubility and Reactivity of Sulfur-Dioxide in Various Oils," Am. Ind. Hyg. Assoc. J. 37(1):46-51, 1976.

17. Beuschlein, W.L. and Simenson, L.O., "Solubility of Sulfur Dioxide in Water," J. Am. Chem. Soc. 62:610-612, 1940.

18. Teetz, C., "Investigation into Reducing Low Temperature Corrosion in Diesel Engines (Beitrag zur Verminderung der Nasskorrosion im Dieselmotor, Nr 626),” Verein Deutscher Ingenieure (VDI), 1984.

19. Reissig, M., Hoppe, A., Buchholz, B., and Hassel, E., "Condensation-Fouling Interaction in Low-Temperature EGR-Coolers,” Matec Web Conf. 18:3004, 2014, doi:10.1051/matecconf/20141803004.

20. Jeong, K. and Levy, E.K., "Theoretical prediction of sulfuric acid condensation rates in boiler flue gas,” Int. J. Heat Mass Transf. 55(25-26):8010-8019, 2012, 
doi:10.1016/j.ijheatmasstransfer.2012.08.037.

21. McKinley, T.L., "Modeling sulfuric acid condensation in diesel engine EGR coolers," SAE Spec. Publ. 1255:207-218, 1997.

22. Land, T., "Theory of Acid Deposition and its Application to the Dew-Point Meter," J Inst Fuel. 50(403):68-75, 1977.

23. Eichelberg, "Some New Investigations on Old Combustion-Engine Problems. I-V," Engineering 148:463-466, 1939.

24. Annand, W.J.D., "Heat Transfer in Cylinders of Reciprocating Internal Combustion Engines,” Inst. Mech. Eng. -- Proc. 177(36):973-996, 1963.

25. Woschni, G., "Universally Applicable Equation for Instantaneous Heat Transfer Coefficient in Internal Combustion Engine,” Soc. Automot. Eng. -- Pap., 1967.

26. Mueller, P., "Dew point temperatures in cylinders of diesel engines working with fuel that contains sulfur (Taupunkttemperaturen im Zylinder von Dieselmaschinen bei schwefelhaltigen Kraftstoffen, Nr 486),” Verein Deutscher Ingenieure (VDI), 1961.

27. Cordtz, R.L., Mayer, S., Schramm, J., and Eskildsen, S.S., "Characteristics of Sulfuric Acid Condensation on Cylinder Liners of Large Two-Stroke Marine Engines.,” 3. Rostocker Großmotorentagung, Rostock, Germany, 2014.

28. Glarborg, P. and Glarborg, P., "Hidden Interactions - Trace Species Governing Combustion and Emissions,” Proc. Combust. Inst. 31:77-98, 2007, doi:10.1016/j.proci.2006.08.119.

29. Hindiyarti, L., Glarborg, P., and Marshall, P., "Reactions of SO3 with the O/H Radical Pool under Combustion Conditions,” J. Phys. Chem. A 111(19):3984-3991, 2007.

30. Rasmussen, C.L., Glarborg, P., and Marshall, P., "Mechanisms of Radical Removal by SO2," Proceedings of the Combustion Institute, ISBN 15407489: 339-347, 2007.

31. Glarborg, P., Kubel, D., DamJohansen, K., Chiang, H.M., and Bozzelli, J.W., “Impact of SO2 and NO on CO Oxidation under Post-Flame Conditions,” Int. J. Chem. Kinet. 28(10):773-790, 1996, doi:10.1002/(SICI)1097-4601(1996)28:10<773::AIDKIN8>3.0.CO;2-K.

32. Ferguson, C.R. and Kirkpatrick, A.T., "Internal combustion engines / applied thermosciences,” Wiley, New York, ISBN 9780471356172; 0471356174, 2001.

33. Nist Chemistry WebBook: http://webbook.nist.gov/chemistry/.

34. Luchinskii, G.P., "Physical-chemical Study of the H2O-SO3 System, I. Equilibrium in the Vapor and the Liquid Phase,” Zh. Fiz. Khim. 30(19):1207-1222, 1956.

35. Incropera, F.P. and DeWitt, D.P., "Fundamentals of Heat and Mass Transfer," J. Wiley, New York, ISBN 9780471457282, 2002, doi:536.2/I36f.4.

36. Mills, A.F., “Mass Transfer,” 2nd ed., Prentice Hall, Inc., New Jersey, 2001.

37. Poschl, U., Canagaratna, M., Jayne, J.T., Molina, L.T., Worsnop, D.R., Kolb, C.E., and Molina, M.J., "Mass Accommodation Coefficient of H2SO4 Vapor on Aqueous Sulfuric Acid Surfaces and Gaseous Diffusion Coefficient of H2SO4 in N2/H2O,” J. Phys. Chem. a 102(49):10082-10089, 1998.

38. Reid, R.C. and Sherwood, T.K., "The properties of gases and liquids. Their estimation and correlation,” McGraw-Hill Book Company, New York, 1958.

39. Turns, S.R., “An introduction to combustion / concepts and applications,” McGraw-Hill, New York, 2012.

40. Bartok, W. and Sarofim, A., "Fossil fuel combustion / A source book," Wiley, New York, 1991.

41. Yahagi, Y., “Corrosive wear of diesel engine cylinder bore,” Tribol. Int. 20(6):365-373, 1987.

42. Kass, M.D., Thomas, J.F., Wilson, D., Lewis, S.A., and Sarles, A., “Assessment of 
Corrosivity Associated with Exhaust Gas Recirculation in a Heavy-Duty Diesel Engine,” Sae Tech. Pap. 2005-01-06, 2005, doi:10.4271/2005-01-0657. 